\title{
O Consumo De Bens E Serviços De Marcas Patrocinadoras De Clubes De Futebol
}

\section{The Consumption Of Goods And Services Of Sponsoring Brands Of Football Teams}

\author{
Edson Roberto Scharf ${ }^{1}$, Gabriel da Silva Pacheco ${ }^{2}$ \\ ${ }^{1}$ Fundação Universidade Regional de Blumenau, FURB, Brasil, ${ }^{2}$ Instituto Federal Catarinense, IFC, Brasil. \\ Correspondência: Edson Roberto Scharf. Rua Antonio da Veiga, 140, Victor Konder CEP 89.010-971, Blumenau, \\ SC, Brasil. Telefone: +55 (47) 3321-0285. E-mail: artigoes@ gmail.com.
}

Recebido: 02 de fevereiro de 2018 Aceito: 19 de outubro de 2018 Publicado: 28 de dezembro de 2018

DOI: http://dx.doi.org/10.21714/1679-18272018v16n2.p167-181

\begin{abstract}
Resumo
O objetivo deste estudo é analisar a probabilidade de que o recall da marca dos patrocinadores e determinados constructos de propensão à lembrança possam influenciar o consumo de bens e serviços relacionados a um clube de futebol. De viés quantitativo, esta pesquisa usa a técnica de regressão logística, escolhida por ser capaz de explicar a probabilidade de ocorrência de um evento partindo de uma variável dependente dicotômica. As variáveis independentes foram compostas por constructos apontados no estudo de Grynberg e Rocha (2010) e pelo recall da marca dos patrocinadores. Os resultados sugerem que os torcedores com alta frequência ao estádio, relativo ao constructo Exposição, e os torcedores que pensam, leem e falam sobre futebol diariamente, relativo ao constructo Interesse, têm maior probabilidade estatística em consumir bens e serviços relacionados ao clube de futebol estudado.
\end{abstract}

Palavras-chave: Marketing no esporte, Consumo, Recall de marca, Patrocínio esportivo, Branding.

\begin{abstract}
The aim of this study is to analyze the likelihood that the brand recall of sponsors and certain mind-bending constructs may influence the consumption of goods and services related to a football club. From a quantitative bias, this research uses the logistic regression technique, chosen to be able to explain the probability of occurrence of an event starting from a dichotomous dependent variable. The independent variables were composed of the constructs pointed out in the Grynberg and Rocha study (2010) and by the brand recall of the sponsors. The results suggest that fans with a high stadium frequency, related to the Exposure construct, and fans who think, read and talk about football daily, regarding the Interest construct, are more statistically likely to consume goods and services related to the football team studied.
\end{abstract}

Keywords: Marketing in sport, Consumption, Brand recall, Sports sponsorship, Branding.

Esta obra está licenciada sob uma Licença Creative Commons Attribution 3.0.

\section{Introdução}

Símbolo da cultura e do imaginário de milhões de adultos e crianças, o futebol extrapola o campo, conduzido com uma devoção que cria uma identidade nacional única, brasileira, reconhecida em todo o planeta. A parte lúdica e humilde deste esporte retratada nas primeiras décadas se transformou, intencionalmente, num produto de alto padrão.

Diante do fascínio dos torcedores, os clubes de futebol do Brasil, seguindo o bem-sucedido modelo europeu, investem na profissionalização de suas equipes dentro e fora das quatro linhas (como é carinhosamente apelidado o campo da peleja). O futebol é uma paixão nacional que vai do gramado até a sala de estar, contando com a prédisposição ao consumo por parte dos torcedores.

A maneira com que os clubes veem o torcedor tem se modernizado. Atualmente, ele é analisado como um consumidor, recebendo iniciativas com a intenção de obter sua lealdade para a aquisição de bens e serviços relacionados a um time. É preciso, segundo Fleury, Alejandro e Feldmann (2014), que os clubes disponibilizem 
qualidade em seus produtos e aumentem a sensação de prazer ao consumidor, ao mesmo tempo em que conseguem receitas financeiras com licenciamento de produtos, ingressos e patrocínios.

Com origem no século XIX, o Marketing no esporte tem gerado grandes oportunidades em termos de imagem, negócio, investimento e receitas financeiras. Este é um importante meio de aproximação com o público, que possui envolvimento afetivo com seu "time do coração", principalmente quando tratamos da realidade brasileira frente ao futebol. Esta relação afetiva está próxima ao que Alba (2012) define como o "orgulho clubístico", ou seja, a expressão de sentimentos e um relacionamento de orgulho para com o clube pelo qual torce.

Há o entendimento de que torcedores de futebol são leais aos seus clubes. No entanto, ainda não é claro que o comportamento dos torcedores seja de lealdade ao seu clube quando se trata de frequentar todos os jogos ou comprar somente produtos oficiais ou que se relacionem ao seu time de coração, segundo Adamson, Jones e Tapp (2006). E Malagrino (2011) adverte que não há tempo ou verbas a serem desperdiçados na conquista de novos consumidores ou no processo de valorização da marca. A via deve ser de mão dupla, no entendimento do autor, devendo ser vantajosa tanto para o patrocinador quanto para o patrocinado.

Neste contexto, o objetivo é analisar a probabilidade de que o recall da marca dos patrocinadores e determinados constructos de propensão à lembrança possam influenciar o consumo de bens e serviços relacionados a um clube de futebol.

\section{Fundamentação Teórica}

Conceitos que facilitam o entendimento da temática e permitem melhor diálogo com os resultados do estudo são apresentados a seguir.

\subsection{Entendendo A Extensão Da Conexão Entre Marketing E Futebol}

Consumidores têm vislumbrado o esporte como meio de satisfazer necessidades de pertencimento a um grupo de identidade e identificação social. Hardy et al. (2004) defende que deve ser diferenciado o Marketing do esporte (bens e serviços esportivos) do denominado Marketing por meio do esporte (bens e serviços pela utilização de promoções esportivas). Sobre a abrangência do Marketing no esporte, em suas diferentes aplicações, Malagrino (2011) sugere que o estudo do Marketing no esporte inclui tanto as estratégias de gestão, comercialização e divulgação de academias, clubes e ligas esportivas, de um lado, quanto as atividades de merchandising, patrocínio e licenciamento que associam equipes ou atletas às marcas.

Esta categoria atualmente denominada de Marketing no esporte, popularmente chamada de Marketing esportivo, surgiu no ano de 1978, na Advertising Age, importante periódico de propaganda, como forma de explicar as estratégias de empresas para promover seus bens e serviços através do esporte. O quadro 1 apresenta que a base está no estudo dos esportes, da administração empresarial, das ciências sociais e da comunicação:

Quadro 1: Áreas associadas ao marketing no esporte.

\begin{tabular}{|c|c|c|c|}
\hline Estudos do Esporte & $\begin{array}{c}\text { Administração de } \\
\text { Empresas }\end{array}$ & Comunicação & Ciências Sociais \\
\hline Filosofia do esporte & Marketing & Jornalismo & Relações humanas \\
\hline Psicologia do esporte & Administração financeira & Relações públicas & Estudos multiculturais \\
\hline Sociologia do esporte & Economia & Estudos de mídia & Estudos populacionais \\
\hline $\begin{array}{c}\text { Administração de } \\
\text { educação física }\end{array}$ & Direito empresarial & Propaganda & $\begin{array}{c}\text { Estudos de mercado de } \\
\text { trabalho }\end{array}$ \\
\hline Administração do lazer & Administração de pessoal & Radiofusão & \\
\hline Administração esportiva & Administração & & \\
\hline
\end{tabular}

Fonte: Pitts e Stotlar (2002).

Quando surgiu, o Marketing no esporte era uma nova disciplina na área da administração, associando marcas de consumo esportivo a atributos como saúde, juventude, conquistas e fama, afirma Malagrino (2011). Em outras palavras, o Marketing no esporte já iniciou suas atividades compreendendo que os benefícios subjetivos que os produtos podem oferecer são diferenciais significativos na ação de compra, fixação de marca e criação de uma identidade para os consumidores. 
Mesmo com características próprias, o Marketing no esporte não difere grandemente do Marketing tradicional. De acordo com Malagrino (2011), estratégias de captação de torcedores são semelhantes às utilizadas na captação de consumidores e podem ser observadas no composto mercadológico: produto (a natureza esportiva do produto, principalmente quanto ao futebol, carrega consigo a necessidade de oferecer algo que extrapole o gramado. Então inclui produtos para distrair o público antes do jogo iniciar, acessórios para a torcida, ou objetos para mostrar seu amor pelo clube); preço (não diz respeito apenas ao valor monetário, mas agrega também tempo, esforço, possibilidade de retorno simbólico positivo e outros); praça (envolve fatores como eventos, compra de ingresso, concessões, imagem do evento, dos jogadores e dos treinadores); e promoção (agências de viagens que vendem pacotes para a Copa do Mundo, patrocínio direito e direto, todas as lembranças possíveis de virar produto).

Até a década de 1980, a Federação Internacional de Futebol (FIFA), órgão máximo do futebol, não permitia que marcas de empresas patrocinadoras fossem estampadas nas camisas dos clubes de futebol. Como meio alternativo, os clubes começaram a vincular seus nomes às empresas que os patrocinavam. Os primeiros exemplos são o Parma da Itália, clube patrocinado pela empresa Parmalat, a Bayer, que adquiriu o time da cidade de Leverkusen, formando o Bayer Leverkusen, e a Philips que formou o PSV, abreviatura do time holandês União Esportiva Philips.

Para Pimentel (2011) a ascensão dessa modalidade comercial se deu realmente depois da década de 90 . Com uma nova visão sobre os torcedores, estes passaram a ser tratados como potenciais consumidores, leais a uma paixão e devotos por seus times do coração. O sucesso desse novo tipo de patrocínio estava em conquistar a simpatia dos torcedores, para que a marca do clube fosse também lembrada.

No Brasil, a Lei no 9.615 de 1998, mais conhecida como Lei Pelé, “[...] reiterou a figura do clube-empresa, exigindo um nível de responsabilidade e profissionalismo semelhantes aos inerentes aos demais tipos de empresas", conforme explica Mattar e Mattar (2013, p.12). Para o autor, os clubes começaram a enxergar o futebol como um produto que poderia ser distribuído de diversas formas, para públicos com gostos e rendas heterogêneas, assim como as empresas ditas tradicionais.

Nesse universo esportivo construído ao longo dos anos, o futebol tem lugar de destaque na cobertura da mídia. Soomoggi (2013) argumenta que através da aquisição do direito de transmissão dos jogos, a televisão se tornou a maior propagadora e uma das principais fontes de renda dos clubes de todo mundo. Movimentando bilhões de dólares anuais em todo o planeta, Malagrino (2011) informa que as três maiores audiências televisivas do planeta comportam eventos esportivos: Copa do Mundo de Futebol, Olimpíadas e o SuperBowl americano.

Para alavancar toda essa estrutura, são necessárias forças de diversas organizações. Na figura 1, se observa alguns desses atores presentes no futebol brasileiro e que auxiliam a este esporte ter crescimento e posição sólida na mente das pessoas.

Figura 1: Atores do futebol brasileiro.

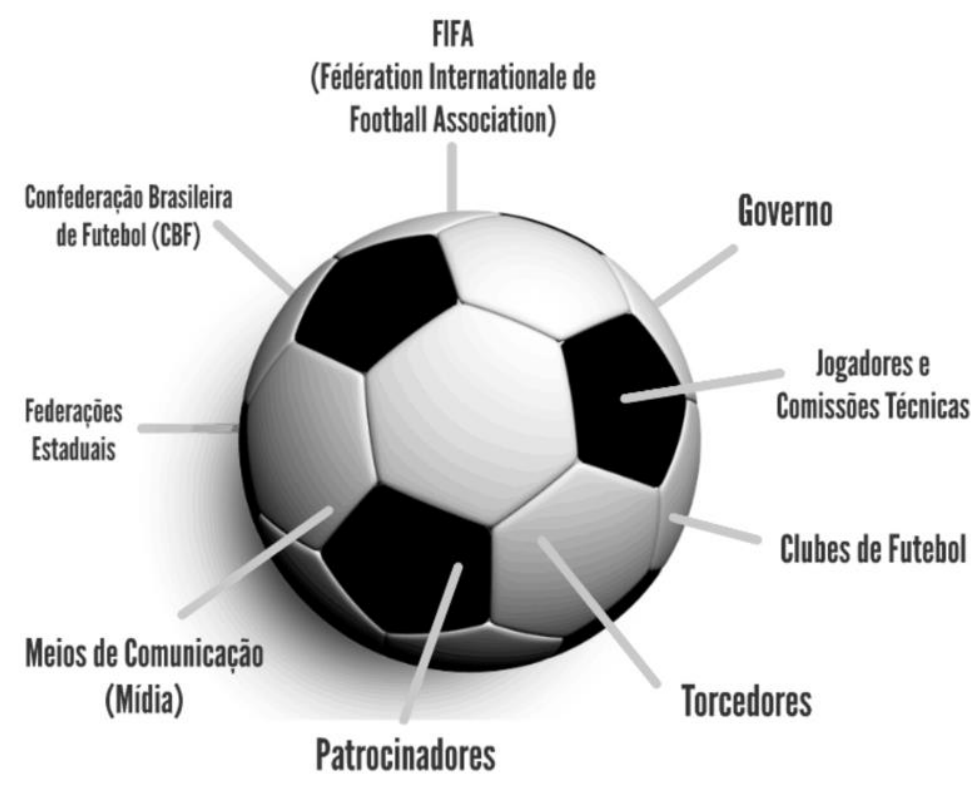

Fonte: adaptado pelos autores de Mosca; Silva; Bastos (2009). 
Essa mercantilização do esporte tem dois lados: elevar o nível do esporte com mais recursos, ao mesmo tempo em que comercializa o que deveria ser lazer. Principalmente quando se trata de futebol, Malagrino (2011) diz não importar mais ter 20 mil torcedores numa arquibancada; é necessário ter 20 mil consumidores no estádio. A partir desse ponto de vista, se percebe que a partida de futebol, vista da ótica do espetáculo business, começa muito antes de o juiz apitar o início do jogo. E o dinheiro arrecadado não é mais proveniente unicamente de bilheteria e venda de produtos ao torcedor. Os clubes têm usado alternativas para aumentar sua rentabilidade, em um nicho de mercado que merece atenção. Capelo (2015) traz um comparativo entre times de futebol e seus países de origem, mostrando que aqueles têm conquistado lucros proporcionalmente maiores que estes:

\begin{abstract}
As receitas de clubes no mundo inteiro cresceram em 2014, em percentual, acima do Produto Interno Bruto (PIB) de cada respectivo país, sinal de que ainda há muito potencial inexplorado pelo futebol, não só no Brasil. Se o PIB brasileiro cresceu $0,1 \%$, o faturamento combinado dos 25 principais times, sem considerar transferências de atletas, aumentou 7\%, de R \$2,58 bilhões em 2013 para R \$2,77 bilhões em 2014. Na Espanha, castigada por uma crise econômica que ainda não acabou e por um alto índice de desemprego, o PIB aumentou 1,4\% em 2014. Já a receita combinada de 23 equipes do país, 7\%, de $€ 1,7$ bilhão para $€ 1,82$ bilhão. Mesmo na Itália, onde o PIB caiu $0,4 \%$ em 2014 , a receita de clubes cresceu pouco, $1 \%$, de $€ 1,16$ bilhão para $€ 1,17$ bilhão, mas cresceu. O mesmo padrão se vê em Inglaterra, França, Alemanha e Argentina, apenas para citar os mais relevantes para o futebol: clubes avançaram mais do que a economia (CAPELO, 2015, p. 1).
\end{abstract}

Essa deficiência de novas fontes de receita no meio esportivo brasileiro, assim como sua dependência dos direitos de transmissão para a mídia televisiva, pode ser observada na figura 2, que apresenta os principais ganhos dos 100 maiores clubes brasileiros em 2012.

Figura 2: Principais fontes de receitas dos clubes de futebol do Brasil em 2012.

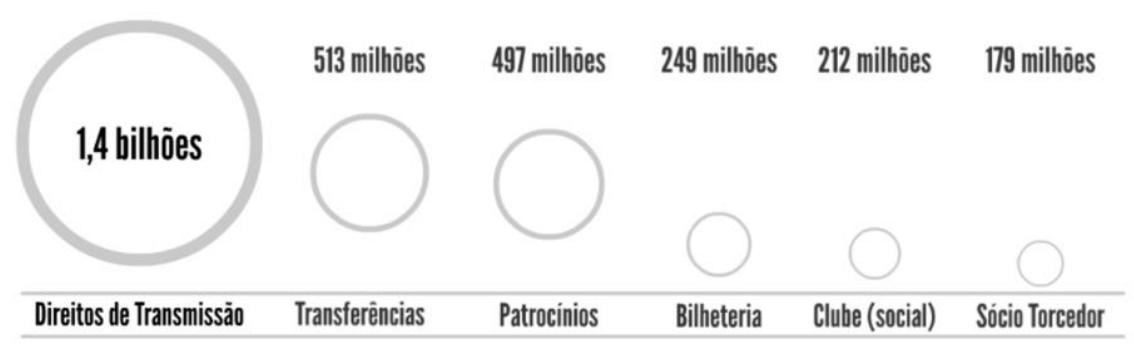

Fonte: adaptado pelos autores de Somoggi (2013).

Os valores presentes no negócio do futebol são vultosos. Apesar de não representarem a maior fatia, os patrocínios e ações de Marketing têm grande destaque para a rentabilidade dos clubes. Malagrino (2011, p. 111) afirma que esta é a era do espetáculo, em uma via de mão dupla: atrair os consumidores para o espetáculo e fazer com que ele se envolva, inclusive consumindo bens e serviços, é a nova missão para os clubes de futebol e seus departamentos de Marketing. Há esforço considerável em encontrar alternativas para aumentar a lucratividade dos clubes, oferecer qualidade ao torcedor e também bons retornos para as empresas patrocinadoras.

Neste sentido, as marcas dos clubes representam força extraordinária na captação de novas oportunidades de negócios. Moraes et al. (2013, p. 231) destacam que a marca e a conexão do indivíduo com ela são os principais influenciadores na intenção de compra. Complementa afirmando que a marca expressa o que o indivíduo é e essa identificação está diretamente relacionada com alta intenção de compra. Esta conexão é produzida na memória dos torcedores por meio de uma série de associações primárias e secundárias. As primárias dizem respeito a lembrança de características, atributos e benefícios associados ao desempenho do produto. As secundárias são abstratas e se associam às memórias do indivíduo, sendo moldadas por aspectos experienciais e simbólicos. Keller (1993) nomeia de brand association as associações do consumidor com a marca. O autor classifica essas associações de acordo com os atributos, os benefícios e as percepções inerentes a cada consumidor.

A empresa que investe em patrocínio esportivo geralmente tem como objetivo principal o reconhecimento da marca, também chamado de brand awareness. O conceito de brand awareness, conforme Scharf (2010, p. 5) "visa identificar o que a marca transmite aos seus clientes e quanto conhecem sobre a empresa". No contexto esportivo, o autor defende que o termo consiste na parcela de visibilidade e reconhecimento da marca patrocinadora, decorrente de variadas formas de exposição, por consequência das ações de patrocínio. Ou seja, o termo recall pode ser definido como a parcela de uma mensagem que fica retida na memória de uma pessoa exposta a um estímulo. Quanto maior a capacidade de retenção, maior a eficiência do esforço de comunicação, segundo Grynberg e Rocha (2010). Morgan e Summers (2008) explicam que o patrocínio vem conquistando espaço no mercado publicitário, estando atrás apenas da publicidade convencional. É, segundo os autores (2008, p. 223), 
uma plataforma de Marketing que pode ser ativada e integrada ao composto mercadológico, podendo incrementar a efetividade e a eficiência das atividades mercadológicas para todos os parceiros da aliança estratégica. Por sua vez, Benazzi e Borges (2008), explicam que o patrocínio inclui várias atividades ligadas a um processo de comunicação, utilizando basicamente o esporte e o estilo de vida das pessoas para atingir seu público. Assim, segundo os autores, há constante aplicação de estratégias de emoção, exposição e vendas que o futebol pode proporcionar.

\subsection{O Futebol E Os Construtos De Conexões Emocionais}

Segundo o dicionário Michelis (2017), constructos são experiências resultantes das percepções inerentes a cada ser humano, que formaram seu conhecimento e sua concepção da realidade. Um constructo, portanto, é uma construção teórica puramente mental, elaborada com dados simples a partir de fenômenos observáveis. $\mathrm{O}$ presente trabalho leva em consideração o conceito de Hair Jr. et al. (2005), para quem um constructo é um conceito, ideias genéricas formadas na mente de alguém. Várias ideias, denominadas eventos, formam um construto, segundo os autores.

Para Kotler e Keller (2012), cada indivíduo é influenciado por uma série de fatores que constituem sua identidade, seu comportamento e seu estilo de vida. Estes fatores atuantes no comportamento do consumidor se dividem em quatro, sendo eles culturais (cultura, subcultura e classes sociais); sociais (grupos de referência, família, papeis e posições sociais); pessoais (idade e estágio do ciclo de vida, ocupação, condições econômicas, estilo de vida e personalidade); e psicológicos (motivação, percepção, aprendizagem, crenças e atitudes).

O ambiente e o convívio social são determinantes na formação da opinião e no comportamento de consumo dos indivíduos. Para Zardini Filho (2012), o comportamento segue um fluxo de interações e é retroalimentado por experiências e axiomas sociais. A Figura 3 apresenta, resumidamente, a ideia do autor.

Figura 3: Modelo resumido de trajetória prévia ao comportamento social.

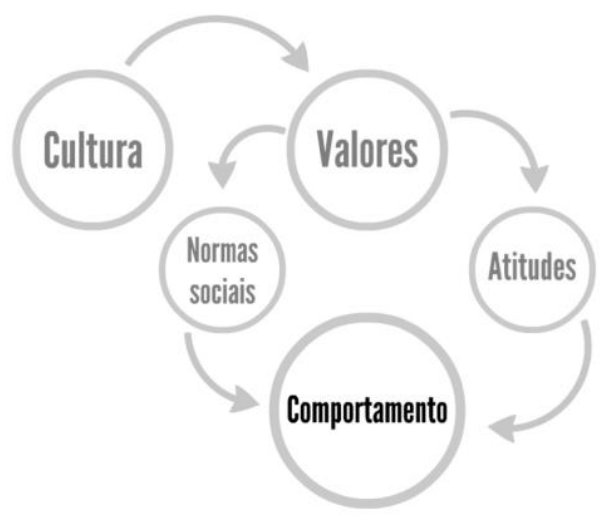

Fonte: adaptado pelo autores de Zardini Filho (2012, p. 69).

Nesse modelo, se observa as influências sofridas pela cultura e por valores individuais, nutridos por normas sociais e atitudes que funcionam como agentes influenciadores de um determinado comportamento. As ações praticadas estão proximamente ligadas à questão emocional, como o indivíduo encara as diferentes situações e como sua memória faz associações a respeito das suas interações. Keller (1993) trata isso como modelos associativos e afirma que nossa memória é formada por um conjunto de nós (armazenadores de informações) que se associam a conexões (que podem ser mais ou menos fortes).

O esporte, por já ser um meio que envolve a emoção, pode provocar reações diferentes nos consumidores. $\mathrm{O}$ futebol, por exemplo, pode ter a capacidade de estimular extremos de emoção, portanto, imprevisíveis. Hoje, um divulgador de rompantes de emoção ligados aos esportes é a mídia de massa, em especial as emissoras de televisão e os canais do repositório de vídeos Youtube.

As associações emocionais produzem uma identidade capaz de determinar o comportamento de um consumidor. Essa identidade, de acordo com Kotler e Keller (2012), é pautada em seus grupos e as posições que eles ocupam. Existem dois níveis de influência na identificação de um fã esportivo com o seu time, segundo Jacobson (2003). Um primeiro nível, interpessoal, ocorre quando torcedores são influenciados por amigos, família ou área geográfica. O segundo nível, simbólico, trata do papel de incentivo que fatores como nome, cor, logomarca e hino do clube possuem. 


\section{Método}

Este é um estudo descritivo, aquele que expõe as características de uma determinada população, descrevendo os fenômenos como eles ocorrem, conforme Vergara (2000). É, por sua natureza, um estudo de caso único. Segundo Yin (2005, p. 32) um estudo de caso "[...] é uma investigação empírica que investiga um fenômeno contemporâneo dentro do seu contexto de vida real, especialmente quando os limites entre o fenômeno e o contexto não estão claramente definidos".

Conforme Hair Jr et al (2005), os planos da pesquisa descritiva se formam no intuito de medir características de um determinado constructo teórico. Foi utilizado o método quantitativo porque aborda os objetivos da pesquisa por meio de avaliações empíricas que envolvem medição e análise numérica. Segundo Zikmund e Babin (2011), o método permite maior compreensão dos dados não-métricos e métricos.

O procedimento survey, aliado a praticidade e alcance da internet, permitiu a coleta dos dados quantitativos em grande escala. Foi utilizada amostra não probabilística por conveniência, ou seja, os torcedores não tiveram chances conhecidas de serem escolhidos e o critério utilizado foi a disponibilidade e a indicação do questionário de um torcedor para outro. Esta indicação é chamada de amostragem bola de neve, conforme Hair Jr. et al. (2010).

Analisando material já publicado sobre o assunto, foi encontrado o trabalho de Grynberg e Rocha (2010), que verificaram a propensão à lembrança e ao índice de recall dos consumidores a respeito das marcas patrocinadoras da Seleção Brasileira de Futebol. Os autores realizaram uma mensuração em escala com constructos já utilizados por Gwinner e Eaton (1999), Gwinner e Swanson (2003) e Grohs et al. (2004), sendo eles: a exposição aos jogos (quanto maior a exposição do torcedor ao patrocínio esportivo, maior será o recall das empresas patrocinadoras), o envolvimento com o clube (estado motivacional que modera o processamento das informações, baseado em suas dimensões cognitivas e afetivas; o envolvimento de fãs se refere à identificação, motivação e afiliação junto a atividades pessoais de lazer), o interesse pelo domínio futebol (faz referência a um campo particular, ao invés de um grupo específico, neste caso, o campo sendo o esporte futebol) e à similaridade funcional e de imagem (a funcional diz respeito à relação existente quando os produtos do patrocinador são utilizados durante o evento patrocinado; a de imagem diz respeito a atributos associados tanto ao patrocinador quanto ao patrocinado, exigindo que o consumidor perceba a conexão de imagem entre os dois). Os resultados e a dinâmica do estudo de Grynberg e Rocha (2010) foram utilizados como base para o trabalho ora desenvolvido.

O objeto de estudo é o Joinville Esporte Clube (doravante JEC). Clube que teve visibilidade nacional ao conquistar os títulos do campeonato brasileiro das séries C e B, respectivamente em 2011 e 2014, tem sua sede em Joinville, interior de Santa Catarina. Algumas ações de Marketing que o clube tem feito correspondem ao licenciamento de produtos, programa sócio-torcedor, TV JEC, patrocínio máster e secundários na camisa, e fornecimento de uniforme. As receitas do JEC são similares a dos grandes clubes brasileiros, citados por Somoggi (2013). Como pode ser visto na figura 4, o clube teve um crescimento significativo nas receitas entre 2013 a 2015, ano em que retornou à Série A do Campeonato Brasileiro de Futebol e recebeu verba pelos contratos televisivos (pouco mais de 17 milhões de reais). Também possui receitas provenientes do programa de sócio torcedor, que arrecadou quase 10 milhões de reais no último ano. Já as cotas de patrocínios e publicidade, ao contrário das outras receitas, teve queda contínua nos últimos 3 anos.

Figura 4: Receitas do JEC entre 2013 e 2015.

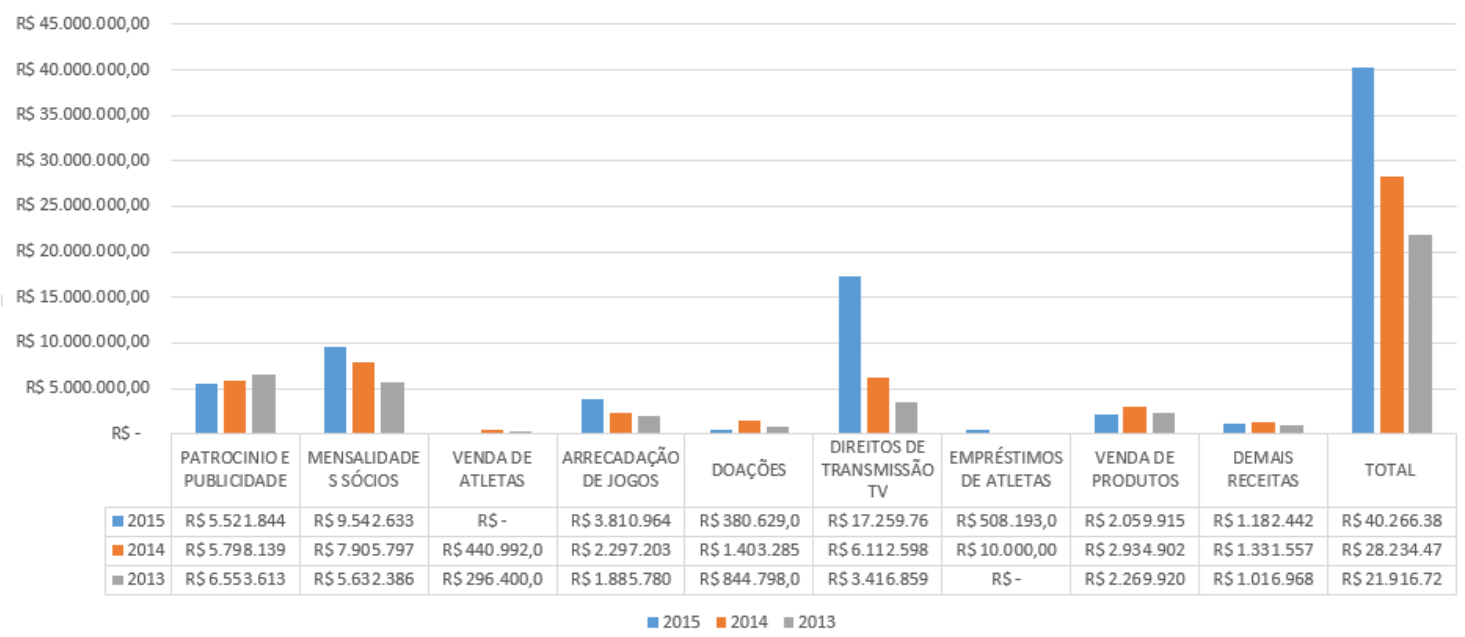

Fonte: Joinville Esporte Clube (2016). 
Para o delineamento deste trabalho, os constructos se relacionam aos conceitos de exposição aos jogos, envolvimento com clube, interesse pelo domínio futebol e similaridade (funcional e de imagem) entre o clube e seus patrocinadores.

Primeiramente, após contatos com funcionários do clube e torcedores, se optou por amostra não probabilística, porém, representativa dos torcedores do JEC, realizada por meio de uma survey. Antes de iniciar a coleta definitiva dos dados por meio de formulário disponível na Internet, foi realizado pré-teste do instrumento, o que possibilitou ajustes.

Com o questionário devidamente adaptado, a pesquisa foi levada adiante de três maneiras: encaminhada por email para um grupo de sócios-torcedores do clube; publicada no grupo oficial da torcida do JEC no Facebook (com mais de 13 mil torcedores); e enviada para grupos pessoais dos pesquisadores na plataforma WhatsApp.

O universo da pesquisa considerou todos os habitantes do município de Joinville que, conforme a última estimativa do IBGE, tem aproximadamente 578 mil habitantes (IBGE, 2017). Mesmo entendendo que nem todos os moradores acompanham, ou mesmo torcem para um clube de futebol, o número pareceu ser mais apropriado quando comparado com a estimativa divulgada pelo clube. Nesta estimativa, o clube informa existirem aproximadamente 750 mil torcedores do JEC na cidade de Joinville e região norte do Estado de Santa Catarina (JOINVILLE, 2017).

Por ser frequentemente utilizada nas pesquisas que envolvem as ciências sociais, se optou pela fórmula de Barbetta (2001):

$$
n_{o}=\frac{1}{\mathrm{E}_{\mathrm{o}}{ }^{2}} \quad n=\frac{N . n_{o}}{N+n_{o}}
$$

Onde: $\mathrm{N}=$ tamanho da população; $E_{o}=$ erro amostral; $n_{o}=$ primeira aproximação do tamanho amostral; $\mathrm{n}=$ tamanho da amostra

Com nível de confiança de $95 \%$ e erro amostral de 5\%, foram entrevistados 385 torcedores do Joinville Esporte Clube. A totalidade das questões foram objetivas e obrigatórias, o que contribuiu para que todos os 385 questionários fossem utilizados na análise quantitativa, com uso da técnica de regressão logística.

A adaptação do questionário original se deu com a criação de afirmativas que pudessem ser respondidas com escala do tipo Likert de 5 pontos, variando entre Discordo Totalmente (1) e Concordo Totalmente (5).

O Quadro 3 apresenta as alterações realizadas para atender as especificidades desta pesquisa. Diferentemente de Grynberg e Rocha (2010), que verificaram a propensão à lembrança e o índice de recall dos consumidores a respeito das marcas patrocinadoras da Seleção Brasileira, esta pesquisa, como maior diferença, tem como objeto de estudo um clube de futebol de abrangência regional. Cabe ressaltar que Grynberg e Rocha (2010) tiveram como referência as pesquisas de Gwinner e Eaton (1999), Gwinner e Swanson (2003) e Grohs et al. (2004), que se referiram respectivamente ao recall de patrocinadores no Campeonato Mundial de Ski Alpino de 2001, ao recall dos patrocinadores de um time universitário de futebol americano, e a um estudo de recall de patrocinadores de acordo com a similaridade percebida entre eles e os eventos patrocinados.

Quadro 3: Constructos adaptados.

\begin{tabular}{|c|c|c|c|c|}
\hline \multirow[t]{2}{*}{$\begin{array}{l}\text { CONSTRUCTOS DO } \\
\text { ESTUDO }\end{array}$} & $\begin{array}{c}\text { AUTOR 1 } \\
\text { GRYNBERG E } \\
\text { ROCHA } \\
(2010)\end{array}$ & $\begin{array}{c}\text { OBJETO } 1 \\
\text { SELEÇÃO } \\
\text { BRASILEIRA DE } \\
\text { FUTEBOL }\end{array}$ & $\begin{array}{l}\text { AUTOR } 2 \\
\text { AUTORES } \\
\quad(2017)\end{array}$ & $\begin{array}{c}\text { OBJETO } 2 \\
\text { JOINVILLE } \\
\text { ESPORTE CLUBE }\end{array}$ \\
\hline & \multicolumn{4}{|c|}{ EVENTOS QUE INFLUENCIAM O RECALL } \\
\hline $\begin{array}{l}\text { EXPOSIÇÃO AOS } \\
\text { JOGOS }\end{array}$ & \multicolumn{2}{|c|}{$\begin{array}{l}\text { O Brasil jogou cinco partidas na Copa do Mundo } \\
\text { de } 2006 \text { (contra Croácia, Austrália, Japão, Gana e } \\
\text { França). Quantas dessas partidas você se recorda } \\
\text { de ter assistido? }\end{array}$} & \multicolumn{2}{|c|}{$\begin{array}{l}\text { Acompanho os jogos do JEC na Arena } \\
\text { Joinville. }\end{array}$} \\
\hline
\end{tabular}




\begin{tabular}{|c|c|c|}
\hline & $\begin{array}{l}\text { Após a Copa do Mundo, o Brasil jogou seis } \\
\text { amistosos (contra Noruega, Argentina, País de } \\
\text { Gales, Kuwait, Equador e Suíça). Quantas dessas } \\
\text { partidas você assistiu? (considerando gravação ou } \\
\text { reprise) }\end{array}$ & $\begin{array}{l}\text { Quando o jogo é em outra cidade, assisto } \\
\text { pela televisão. }\end{array}$ \\
\hline \multirow{4}{*}{ ENVOLVIMENTO } & $\begin{array}{l}\text { Sempre que a Seleção Brasileira de Futebol joga, } \\
\text { assisto discussões e reportagens, do tipo "mesas } \\
\text { redondas" e "melhores momentos", antes ou } \\
\text { depois dos jogos. }\end{array}$ & $\begin{array}{l}\text { Antes e depois do jogo, acompanho } \\
\text { discussões e reportagens, do tipo "mesas } \\
\text { redondas" e "melhores momentos". }\end{array}$ \\
\hline & $\begin{array}{l}\text { Depois que a Seleção Brasileira de Futebol joga, } \\
\text { costumo participar de discussões sobre o jogo } \\
\text { com amigos de trabalho, de estudos ou em casa. }\end{array}$ & $\begin{array}{l}\text { Depois do jogo, costumo participar de } \\
\text { discussões com amigos de trabalho, de } \\
\text { estudos ou em casa. }\end{array}$ \\
\hline & $\begin{array}{l}\text { Quando a Seleção Brasileira de Futebol perde, } \\
\text { fico chateado ou irritado no dia seguinte ao jogo. }\end{array}$ & $\begin{array}{l}\text { Quando o JEC perde, fico chateado ou } \\
\text { irritado no dia seguinte ao jogo. }\end{array}$ \\
\hline & $\begin{array}{l}\text { Quando vejo alguém criticando a Seleção } \\
\text { Brasileira de Futebol (colegas, pessoas de outros } \\
\text { países ou mesmo a imprensa internacional) me } \\
\text { sinto incomodado. }\end{array}$ & $\begin{array}{l}\text { Quando vejo alguém criticando o JEC (como } \\
\text { imprensa, amigos, etc.) me sinto } \\
\text { incomodado. }\end{array}$ \\
\hline \multirow{3}{*}{$\begin{array}{l}\text { INTERESSE PELO } \\
\text { FUTEBOL }\end{array}$} & Eu adoro futebol. & Eu adoro futebol. \\
\hline & $\begin{array}{l}\text { Costumo pensar, ler ou falar sobre futebol } \\
\text { diariamente. }\end{array}$ & $\begin{array}{l}\text { Costumo pensar, ler ou falar sobre futebol } \\
\text { diariamente. }\end{array}$ \\
\hline & Eu assisto futebol sempre que posso. & Eu assisto futebol sempre que posso. \\
\hline \multirow{4}{*}{$\begin{array}{l}\text { SIMILARIDADE } \\
\text { FUNCIONAL E } \\
\text { IMAGEM }\end{array}$} & $\begin{array}{l}\text { É provável que jogadores da Seleção Brasileira } \\
\text { de Futebol usem produtos da EMPRESA X } \\
\text { durante os jogos. }\end{array}$ & \multirow{2}{*}{$\begin{array}{l}\text { Quando assisto aos jogos do JEC, vejo } \\
\text { produtos dos patrocinadores sendo utilizados } \\
\text { pelos atletas. }\end{array}$} \\
\hline & $\begin{array}{l}\text { Quando assisto aos jogos da Seleção Brasileira de } \\
\text { Futebol, vejo produtos da EMPRESA X sendo } \\
\text { usados. }\end{array}$ & \\
\hline & $\begin{array}{l}\text { A Seleção Brasileira de Futebol e a EMPRESA X } \\
\text { têm uma imagem semelhante. }\end{array}$ & \multirow{2}{*}{$\begin{array}{l}\text { As ideias que eu associo aos Patrocinadores } \\
\text { são semelhantes às ideias que eu associo ao } \\
\text { JEC. }\end{array}$} \\
\hline & $\begin{array}{l}\text { As ideias que eu associo à EMPRESA X são } \\
\text { semelhantes às ideias que eu associo à Seleção } \\
\text { Brasileira de Futebol. }\end{array}$ & \\
\hline
\end{tabular}

Fonte: Autores (2017).

Os eventos que tiveram alterações mais significativas estão relacionados aos constructos de Exposição e Similaridade. Conforme consta no Quadro 3, nos estudos de Grynberg e Rocha (2010) a Exposição foi medida computando a quantidade de partidas assistidas pelo torcedor (somente pela televisão) em determinado período de tempo. Neste estudo, por se tratar de um clube com características regionais, os eventos de Grynberg e Rocha (2010) relacionados ao constructo Exposição (assistir aos jogos da seleção pela televisão) foram substituídos pela frequência ao estádio, quando o jogo é em Joinville, e pela frequência em assistir os jogos do JEC pela televisão, quando este é em outra cidade. Já os eventos relacionados à similaridade funcional e de imagem foram condensados de 4 para 2 eventos.

Com o objetivo de aumentar a adesão dos torcedores, o questionário foi desenvolvido no serviço de formulários Google, e teve como premissa ser rápido e fácil de responder. O único critério de filtro foi ser um torcedor do clube. O questionário foi dividido em cinco seções. Todas as vinte e cinco perguntas foram obrigatórias, ou seja, o torcedor respondente não poderia progredir nas seções do questionário se uma pergunta estivesse sem resposta, assim como não tinha a possibilidade de editar as mesmas após o envio.

O torcedor foi orientado a utilizar sua memória espontânea, sem consultar em fontes externas, na seção que avaliou o reconhecimento da marca dos patrocinadores do clube. Foram 5 opções de marcas patrocinadoras, além da opção "outro" e da opção "não lembro", todas no modo randômico, ou seja, para cada respondente a ordem das respostas alternava. O critério de escolha das marcas foi subjetivo e teve como referência alguns dos 
últimos patrocinadores exibidos no sítio eletrônico do clube. Vale ressaltar que as marcas não apresentavam suas características de representação como, por exemplo, cor, fonte, formas diversas. Dessa maneira, apenas com a escrita das marcas em ordem aleatória, a memória do torcedor foi mais exigida, ficando incapaz de fazer associações que só seriam possíveis vendo a marca em seu formato original.

Com a atual facilidade de acesso à Internet e de um substancial interesse dos torcedores pelo tema, a pesquisa foi sendo rapidamente reencaminhada e preenchida por diferentes perfis de torcedores até completar o total estipulado de 385 respondentes. Os dados coletados foram revisados e codificados antes de serem submetidos ao software estatístico SPSS. Primeiramente, foi realizada uma análise descritiva que, mesmo sendo uma técnica simples, segundo Zikmund e Babin (2011), é extremamente eficaz quando o objetivo é resumir uma grande quantidade de dados e fazer inferências sobre as características de uma população alvo. Para facilitar as análises, se optou pelo uso de tabulação cruzada e tabelas de contingência. Conforme Zikmund e Babin (2011, p. 415-416) a tabulação cruzada é a "técnica adequada para lidar com perguntas de pesquisa envolvendo relações entre múltiplas variáveis". Já a tabela de contingência, para os mesmos autores, "é uma matriz de dados que exibe a frequência de algumas combinações de possíveis reações a variáveis múltiplas".

Com os dados codificados, a técnica estatística para o alcance dos objetivos foi regressão logística. Para o alcance dos dois primeiros objetivos, foi considerada como variável dependente $(\mathrm{Y})$ o ato de comprar ou não e como variáveis independentes $(\mathrm{X})$ os constructos e seus respectivos eventos. Por fim, para verificar se os torcedores com recall assertivo dos patrocinadores têm probabilidade de compra superior aos demais, a amostra foi filtrada tendo como critério de escolha somente os torcedores que responderam corretamente às questões 12,13 e 14 . Respectivamente, perguntavam ao torcedor se ele lembrava quem é o patrocinador atual do clube; quem era o patrocinador no título da Série C, em 2011; e quem era o patrocinador no título da Série B, em 2014.

Para garantir que as classificações e predições baseadas na equação logística fossem mais acertadas do que as que poderiam ser realizadas avaliando somente a análise de frequência das respostas, foram utilizadas como medidas de avaliação testes de significância estatística para modelos logísticos, como o Likelihood Value, Model Chi-square (que testou a hipótese de que todos os coeficientes da equação logística fossem nulos), os testes Cox-Snell $\mathrm{R}^{2} \mathrm{e}$ Nagelkerke $\mathrm{R}^{2}$, Hosmer e Lemeshow (para verificar a existência de diferenças significativas entre as classificações realizadas), e o teste de Wald (para aferir o grau de significância de cada coeficiente da equação logística, inclusive da constante).

\section{Apresentação Dos Resultados E Discussão}

Os 385 torcedores respondentes foram submetidos a uma análise de agrupamento para verificar a possibilidade de formação de novos grupos dentro da amostra. Não foram encontradas características significativamente capazes de justificar a divisão dos torcedores em grupos.

Com relação a origem dos torcedores respondentes, não houve surpresa: o total de $59 \%$ nasceu e ainda mora em Joinville, seguido por $31 \%$ de torcedores que nasceu em outra cidade, mas que atualmente mora em Joinville e torce para o JEC. Como $90 \%$ dos torcedores reside em Joinville, se confirma a regionalidade do clube.

O gênero masculino representa a maioria dos torcedores que também é consumidora (74\%). As mulheres ainda são minoria (11\%). As torcedoras que mais consomem bens e serviços relacionados ao clube estão entre a faixa de 19 a 25 anos, o que representa $6 \%$ da amostra. Entre os homens, o conjunto de $22 \%$ dos torcedores e consumidores têm entre 26 e 35 anos.

Os torcedores do clube apresentam um alto índice de instrução escolar. Apenas $2 \%$ da amostra parou os estudos no ensino fundamental, enquanto $48 \%$ dos torcedores está cursando ou já terminou um curso superior, e 29\%, um curso de pós-graduação.

Com relação a renda, $9 \%$ dos torcedores não tem salário e depende financeiramente de outra pessoa. Mesmo assim, $8 \%$ deles, 30 torcedores, lembrou de ter feito ao menos uma compra associada ao JEC no último ano. A maioria dos torcedores do clube (33\%) afirmou receber entre $\mathrm{R} \$ 3.884,00$ e $\mathrm{R} \$ 9.710,00$, equivalente a 4 até 10 salários mínimos. Apenas $1 \%$ tem renda acima de 20 salários mínimos. A tendência de compra foi similar ao que ocorreu na instrução escolar, ou seja, quanto maior a renda, maior o consumo.

Os sócios torcedores representam $68 \%$ da amostra. Deste total, apenas 3\% declarou não ter comprado nenhum bem ou serviço associado ao clube. O clube, que já chegou a ter 12 mil sócios, amarga uma drástica diminuição no número de sócios após o rebaixamento para a série C, em 2016. Scharf $(2016$, p.23) explica que o futebol é um esporte passional e imprevisível: "[...] quando os resultados são aquém do esperado, diminuem as receitas das bilheterias e reduz o tempo de exposição na mídia." Isso explica, em parte, o momento atual do JEC e reafirma que existe uma relação entre o desempenho dentro de campo com o número de sócios. Ghose (2009) advoga que os clientes avaliam as suas experiências a partir das expectativas criadas sobre o que a marca representa, em 
percepções adquiridas por uma série de fatores, alguns deles incontroláveis pela organização. Essas expectativas sugeridas pelo autor aumentam a possibilidade de o torcedor realizar compras de bens ou serviços disponibilizados pelo time de futebol. Há componentes de pertencimento e de exclusividade quando o torcedor se conecta ao clube. Neste sentido, Arnold et al. (2005) sugerem que consumidores incluem em suas experiências de compra alguns elementos de identificação, exclusividade e entretenimento, com o desejo de se tornar uno com o seu grupo.

Mensurar o retorno em patrocínio esportivo de forma quantitativa é algo complexo, segundo Grynberg e Rocha (2010), devido a quantidade de variáveis que atuam similar e simultaneamente. Diante desta complexidade, a seguir são feitas discussões para buscar explicar padrões de comportamento do torcedor de futebol relacionados ao consumo.

O constructo Exposição, relacionado a frequência ao estádio, demonstrou ter uma forte relação com o consumo de bens e serviços associados ao clube e vem ao encontro do que Scharf (2016, p. 22) ressalta como importante na experiência com as atividades de patrocínio esportivo: "uma experiência marcante, portanto, permite a fixação da marca patrocinadora ao mesmo tempo em que os consumidores participam ativamente da atividade". Autores diversos, como Abrahams (1986), Carù e Cova (2003) e Yuan e Wu (2008), defendem que experiências são inerentemente individuais e devem levar à satisfação do consumidor, por meio de elementos funcionais e emocionais, respectivamente a qualidade do serviço ou bem e as sensações envolvidas. Nos estádios de futebol ocorrem sentimentos diferentes a todo momento, seja no contato com o time, com os serviços ou com outros torcedores, seja com o momento êxtase pela alegria de um gol ou de uma vitória. Portanto, estar presente no estádio amplia a experiência e facilita o consumo. Carù e Cova (2003), neste tocante, sugerem que experiências extraordinárias desenvolvem sentimentos de triunfo, podendo até transformar os indivíduos nela envolvidos. Estes sentimentos positivos podem ser fatores de predisposição ao consumo de objetos ligados ao clube.

Por meio da técnica de regressão logística, considerada como variável dependente os torcedores que são consumidores ou não, e como variáveis independentes os constructos (Exposição, Envolvimento, Interesse e Similaridade), são elencados na tabela 1 os constructos e eventos conforme sua influência no consumo. O principal indicador para a significância estatística é o "Sig.", que deve conter um valor igual ou inferior 0,05 para ser considerado pelo cálculo, segundo Corrar et al. (2009).

Tabela 1: Constructos que mais influenciam o torcedor a comprar.

\begin{tabular}{|c|c|c|c|c|c|c|c|}
\hline Constructos & Eventos & $\beta$ & S.E & Wald & df & Sig. & $\operatorname{Exp}(B)$ \\
\hline Exposição & $\begin{array}{l}\text { Acompanho os jogos do JEC na Arena } \\
\text { Joinville (Estádio) }\end{array}$ &, 721 &, 146 & 24,536 & 1 &, 000 & 2,056 \\
\hline Interesse & $\begin{array}{l}\text { Costumo pensar, ler ou falar sobre } \\
\text { futebol diariamente (Pensa) }\end{array}$ & ,380 & ,194 & 3,822 & 1 &, 051 & 1,462 \\
\hline $\begin{array}{l}\text { Envolviment } \\
\text { o }\end{array}$ & $\begin{array}{l}\text { Antes ou depois do jogo, acompanho } \\
\text { discussões e reportagens, do tipo } \\
\text { "mesas redondas" e "melhores } \\
\text { momentos" }\end{array}$ & ,243 &, 170 & 2,043 & 1 &, 153 & 1,275 \\
\hline Exposição & $\begin{array}{l}\text { Quando o jogo é em outra cidade, } \\
\text { assisto pela televisão }\end{array}$ &, 180 &, 148 & 1,493 & 1 & ,222 & 1,197 \\
\hline $\begin{array}{l}\text { Similaridade } \\
\text { e Imagem }\end{array}$ & $\begin{array}{l}\text { Quando assisto aos jogos do JEC, vejo } \\
\text { produtos dos patrocinadores sendo } \\
\text { utilizados pelos atletas }\end{array}$ & ,157 &, 160 & ,959 & 1 & 327 & 1,170 \\
\hline $\begin{array}{c}\text { Envolviment } \\
\text { o }\end{array}$ & $\begin{array}{l}\text { Quando o JEC perde, fico chateado ou } \\
\text { irritado no dia seguinte ao jogo }\end{array}$ &,- 119 &, 161 & ,549 & 1 & ,459 & ,888 \\
\hline $\begin{array}{l}\text { Envolviment } \\
\text { o }\end{array}$ & $\begin{array}{l}\text { Depois do jogo, costumo participar de } \\
\text { discussões com amigos de trabalho, de } \\
\text { estudos ou em casa }\end{array}$ &,- 072 &, 166 & ,191 & 1 & 662 & ,930 \\
\hline Interesse & Eu adoro futebol &,- 107 & ,249 &, 184 & 1 & 668 & 899 \\
\hline $\begin{array}{l}\text { Envolviment } \\
\text { o }\end{array}$ & $\begin{array}{l}\text { Quando vejo alguém criticando o JEC } \\
\text { sinto-me incomodado }\end{array}$ &, 056 &, 167 &, 112 & 1 &, 738 & 1,057 \\
\hline $\begin{array}{l}\text { Similaridade } \\
\text { e Imagem }\end{array}$ & $\begin{array}{l}\text { As ideias que eu associo aos } \\
\text { Patrocinadores são semelhantes às } \\
\text { ideias que eu associo ao JEC }\end{array}$ &, 027 & , 169 & 025 & 1 & 873 & 1,027 \\
\hline
\end{tabular}




\begin{tabular}{lllllllll}
\hline Interesse & Eu assisto futebol sempre que posso &,- 034 &, 222 &, 024 & 1 &, 878 &, 966 \\
\hline Constante & & $-2,903$ &, 848 & 11,724 & 1 &, 001 &, 055 \\
\hline
\end{tabular}

Fonte: Autores (2017).

Os constructos e eventos com maior significância estatística foram submetidos novamente ao software SPSS, obtendo melhor ajustamento, conforme apontados na tabela 2. Comparados com a tabela anterior, se observa um aumento expressivo no valor de Beta $(\beta)$ e de Sig., principalmente no constructo relacionado ao interesse.

Tabela 2: Regressão múltipla isolando as variáveis mais representativas.

\begin{tabular}{clcccccc}
\hline Construto & \multicolumn{1}{c}{ Fator } & $\boldsymbol{\beta}$ & S. E & Wald & df & Sig. & Exp(B) \\
\hline Exposição & $\begin{array}{l}\text { Acompanho os jogos do JEC na Arena } \\
\text { Joinville (Estádio) }\end{array}$ &, 803 &, 130 & 38,138 & 1 &, 000 & 2,231 \\
\hline Interesse & $\begin{array}{l}\text { Costumo pensar, ler ou falar sobre futebol } \\
\text { diariamente (Pensa) }\end{array}$ &, 398 &, 127 & 9,798 & 1 &, 002 & 1,489 \\
Constante & $-2,279$ &, 523 & 18,977 & 1 &, 000 &, 102 \\
\hline
\end{tabular}

Fonte: Autores (2017).

Portanto, considerando apenas os eventos com valor igual ou inferior a 0,05 , os únicos constructos que obtiveram significância estatística relacionada ao consumo foram o de Exposição (evento: acompanha jogos no estádio, com Sig. 0,000) e o de Interesse (evento: pensa, lê e fala sobre futebol diariamente, com Sig. 0,002).

Nos estudos de Grynberg e Rocha (2010), o grau de exposição dos espectadores às marcas e jogos, assim como o seu grau de envolvimento com a Seleção Brasileira, não se revelaram suficientemente fortes para fazer com que as marcas patrocinadoras da seleção canarinho fossem lembradas ou reconhecidas. A pesquisa dos autores demonstrou que o interesse por futebol tem maior capacidade de explicar a variação do recall dos patrocinadores e que a percepção de similaridade contribui de formas distintas para cada patrocinador. É possível, segundo Grynberg e Rocha (2010), que os torcedores tenham dificuldade em fazer a conexão entre a atividade de um patrocinador e a marca patrocinada. Isso pede uma reflexão de quão importante é a sintonia entre a imagem da marca, desenhada mentalmente pelo torcedor, e a identidade divulgada pela organização anunciante. Martinez e Chernatony (2004) sugerem que quando há essa conexão, os consumidores têm níveis mais elevados de propensão a preferir marcas com as quais se identifica. Ao mesmo tempo, os autores sugerem que os consumidores desfrutam de níveis elevados de satisfação quando consomem estas marcas.

Embora ficando abaixo da significância estatística satisfatória, o constructo Envolvimento (acompanhar notícias antes e depois dos jogos), também demonstra ser relevante para o consumo. Grynberg e Rocha (2010) argumentam que em clubes, ao contrário de uma seleção nacional, o torcedor tem um relacionamento diário com o time, o que facilitaria inclusive no reconhecimento e lembrança dos patrocinadores. A mensuração do relacionamento que os consumidores possuem com determinada marca, seu brand awareness, apresenta resultados positivos quanto mais emoção houver na relação, segundo Adamson et al. (2006). Isto porque as pessoas, e mais especialmente os torcedores, se desviam de avaliações racionais em relação às suas paixões, deixando o sentimento de euforia absorver os aspectos eventualmente menos positivos do clube, conforme os autores. Há, portanto, ampliação do envolvimento do torcedor com o time de futebol, que busca mais informações positivas e se dispõe a conversar sobre isto com outros torcedores e simpatizantes do mesmo clube.

Além dos "produtos oficiais" do clube, o JEC oferece aos seus torcedores e simpatizantes os "produtos licenciados" (empresas que utilizam a marca do clube em troca de porcentagem nas vendas) e, aos sócios, descontos exclusivos do programa de benefícios "clube do coelho". Também na lista estão os "produtos dos patrocinadores", pois ainda que o patrocinador não tenha como foco principal a venda direta ao torcedor, ela sempre figura entre as principais motivações para o patrocínio esportivo.

Nesta pesquisa, o conjunto de $35 \%$ dos torcedores comprou ao menos um bem ou serviço relacionado ao JEC no último ano. Analisando todas as combinações de compra, é preciso destacar o conjunto de $28 \%$ dos torcedores que só comprou "produtos oficiais", 15\% comprou produtos "licenciados e oficiais", e 10\% que comprou todas as opções disponíveis ao torcedor e ao sócio do clube. Gaspar et al (2014) afirmam que é comum encontrar nas lojas oficiais variados artigos e objetos sendo vendidos por preços superiores aos itens similares que não tenham a marca do clube. A oportunidade de oferecer estes itens ao torcedor atrai, aproxima e aumenta o relacionamento entre torcedores e o clube, segundo os autores, o que gera mais valor ao produto, tornando o preço justificável e aceitável 
pelo público pagante. O conhecimento da marca é o significado pessoal a respeito de uma marca armazenado na memória do consumidor, segundo Keller (1993), incluindo informações descritivas e avaliativas relacionadas a ela. Para o autor, este conhecimento pode ocorrer de diversas maneiras, permitindo que qualquer encontro com uma marca permita a alteração da representação mental a respeito dela e, também, daquilo que figura na mente do consumidor, a exemplo de preço alto, benefício ou exclusividade.

Finalmente, para verificar a probabilidade de um torcedor comprar bens e serviços relacionados ao clube, seus patrocinadores e parceiros comerciais, foi utilizada a seguinte equação logística:

$$
Z=-2,279+(0,803) \times \text { Estádio }+(0,398) \times \text { Pensar }
$$

Apenas os constructos com significância estatística puderam ser utilizados para estimar a probabilidade. Neste caso, a letra " $Z$ " corresponde à variável dependente (comprar sim/não), seguido do valor da constante $(-2,279)$ somado ao valor de Beta $(0,803)$ vezes o evento Estádio (constructo Exposição) somando novamente com Beta $(0,398)$, multiplicado ao evento Pensar (constructo Interesse).

Os resultados mostram que os torcedores do JEC que frequentam o estádio em dias de jogo (constructo Exposição) e aqueles que pensam, leem e falam sobre futebol diariamente (constructo Interesse) têm, respectivamente, $80 \%$ e $39 \%$ de probabilidade em comprar bens e serviços relacionados ao clube. Organizações têm adotado a experiência de marca como base das suas estratégias mercadológicas. Para Brakus et al. (2009), é por meio dela que ocorre o fornecimento de valores sensoriais, emocionais, sociais, cognitivos e comportamentais ao target. Como processo de envolvimento com o consumidor, a experiência de marca se apresenta como um conjunto de ações que conecta o desempenho das empresas, os estímulos proporcionados e as emoções lembradas com as expectativas do indivíduo quando efetua o contato com a marca, segundo os autores. É preciso também observar nesses resultados a amplitude das emoções envolvidas quando o torcedor se encontra no estádio ou discute com amigos sobre o seu time. Brakus et al. (2009) advogam que a experiência de marca varia segundo a força e a intensidade com que são sentidas e podem variar, também, na avaliação, se mostrando positiva ou negativa. Neste sentido, Walter et al. (2013) afirmam que a maioria das decisões de compra é de caráter emocional, o que pede especial atenção à compreensão da influência dos sistemas sensoriais no comportamento de consumo.

Para verificar se os torcedores com recall assertivo dos patrocinadores têm probabilidade de compra superior aos demais torcedores, a amostra foi dividida, tendo como filtro somente os torcedores que acertaram o recall relacionado às questões 12, 13 e 14. As perguntas e quantidade de acerto podem ser vistas na tabela 3:

Tabela 3: Amostra selecionada para regressão logística.

\begin{tabular}{|c|c|c|c|}
\hline \multirow{2}{*}{ Questões } & \multirow{2}{*}{ Resposta certa } & \multicolumn{2}{|c|}{ Total } \\
\hline & & Acerto & $\%$ \\
\hline $\begin{array}{l}\text { 12. Na sua visão, quem é o Patrocinador Máster do } \\
\text { JEC em } 2016 \text { ? }\end{array}$ & Não tem & 48 & $12,46 \%$ \\
\hline $\begin{array}{l}\text { 13. No título da Série C, em 2011, qual dessas } \\
\text { empresas era o Patrocinador Máster? }\end{array}$ & Taipa & 186 & $48,31 \%$ \\
\hline $\begin{array}{l}\text { 14. No título da Série B, em 2014, qual dessas } \\
\text { empresas era o Patrocinador Máster? }\end{array}$ & Romaço & 196 & $50,90 \%$ \\
\hline
\end{tabular}

Fonte: Autores (2017).

Do total de respondentes, $10 \%$ alegou não saber quem é o patrocinador, e apenas $13 \%$ disse que o JEC não tem patrocinador máster em 2016, considerada a resposta certa nesta pesquisa. Naquele ano, o JEC não fechou contrato de patrocínio máster (principal).

O único recall que apresentou significância estatística relacionado a variável dependente "compra" foi o relacionado à marca Taipa no título brasileiro da série C, conquistado em 2011. A tabela 4 apresenta os testes de significância:

Tabela 4: Regressão logística isolando o recall mais representative.

\begin{tabular}{lllllll}
\hline Recall & B & S.E & Wald & df & Sig. & $\operatorname{Exp}(B)$ \\
\hline
\end{tabular}




\begin{tabular}{lcccccc}
\hline Título Série C (Taipa) &, 189 &, 077 & 5,983 & 1 &, 014 & 1,208 \\
\hline Constante &, 900 &, 354 & 6,470 & 1 &, 011 & 2,459 \\
\hline
\end{tabular}

Fonte: Autores (2017).

Dessa forma, para prever a probabilidade de o recall da marca influenciar no consumo de bens e serviços dos patrocinadores e parceiros comerciais do JEC, foi utilizada a seguinte equação logística: $Z=0,900+(0,189) \mathrm{x}$ Taipa, em que a variável dependente $(Z)$ é igual a constante $(0,900)$ mais Beta $(0,189)$ multiplicado pela marca Taipa. O resultado apontou que o torcedor com recall da marca Taipa, relacionada ao título de 2011, tem $18 \%$ de probabilidade de comprar bens e serviços relacionados ao JEC.

Portanto, os resultados encontrados neste estudo demonstram que o recall do patrocinador tem baixa relação com o consumo, ainda que a marca tenha alto índice de lembrança por parte do torcedor. Isso pode estar associado ao fato de que vincular a marca a um determinado time de futebol já não é mais suficiente para ter êxito em mercados competitivos, conforme o entendimento de Scharf (2016).

\section{Considerações Finais}

O objetivo deste estudo foi analisar a probabilidade de o recall da marca dos patrocinadores e determinados constructos de propensão à lembrança influenciarem o consumo de bens e serviços relacionados a um clube de futebol.

Conquanto Grynberg e Rocha (2010) não encontraram relevância estatística nos constructos Exposição e Envolvimento que pudessem justificar o recall dos patrocinadores da Seleção Brasileira de Futebol, esta pesquisa demonstrou que o torcedor do JEC que frequenta assiduamente o estádio em dias de jogo (constructo Exposição) tem $80 \%$ de probabilidade na aquisição de bens e serviços relacionados ao clube e seus parceiros comerciais. $\mathrm{O}$ constructo Envolvimento não teve relevância estatística para predizer a relação de consumo, tal qual o estudobase. No entanto, por apresentar resultado muito próximo nas tabelas de frequência, demonstra que o torcedor do JEC tem alto envolvimento com seu time, o que poderia ser melhor explorado para uma relação de consumo.

Já o constructo Interesse pelo domínio Futebol demonstrou ser relevante tanto para o recall dos patrocinadores na pesquisa de Grynberg e Rocha (2010) quanto para o consumo de bens e serviços relacionados ao JEC. Nesse estudo, o torcedor que pensa, lê e fala diariamente sobre futebol (constructo Interesse) tem 39\% de probabilidade de compra relacionada a bens e serviços oferecidos pelo clube e seus parceiros. Não é uma probabilidade tão expressiva quando comparada ao constructo Exposição (frequência ao estádio), mas demonstra que o interesse pelo esporte é fundamental para que ações de patrocínio esportivo para apoio à marca sejam bem-sucedidas.

A imprevisibilidade do esporte pode refletir nos resultados do Marketing, mas o grau de identificação da torcida com sua equipe pode ampliar os resultados conquistados pelas empresas que tem seus nomes associados ao clube, independentemente do resultado dentro de campo. O futebol é uma indústria em expansão, que requer renovação e possui clientes ávidos por novidades e experiências. Este estudo demonstrou que a experiência de ir ao estádio é o fator que mais influencia o torcedor a comprar produtos relacionados ao seu clube e que, portanto, deveria ser melhor explorada por empresas e clubes.

Nesse sentido, se conclui que os constructos analisados tiveram maior influência no comportamento de consumo dos torcedores do que o recall da marca dos patrocinadores.

Como implicações gerenciais os resultados deste estudo apontam que a experiência de viver o futebol, seja acompanhando notícias ou indo ao estádio, é uma possibilidade que as empresas que buscam gravar suas marcas na mente e no coração dos torcedores devem aperfeiçoar. Assim sendo, mais ações de patrocínio esportivo deveriam ser realizadas nos estádios e seus arredores, antes, durante e depois da partida.

Quanto às implicações acadêmicas, os resultados do estudo apontam para o aprofundamento teórico sobre o impacto da experiência no consumo, assim como a identificação de outros constructos que possam auxiliar acadêmicos a buscar novos campos de conhecimento a partir da paixão do torcedor por seu clube.

Quanto às limitações do presente estudo, há o fato de não ter sido utilizada uma amostra probabilística da população em estudo, o que permitiria generalizações para outras regiões com características similares. Portanto, outros estudos podem ser levados a cabo com o uso de amostras probabilísticas e outras técnicas de análise e coleta de dados, adicionando à amostra outros atores envolvidos, como dirigentes dos clubes e torcedores. É de importância para futuros trabalhos de pesquisa que a perspectiva do patrocinador seja compreendida. 


\section{Referências}

ABRAHAMS, R. D. Ordinary and extraordinary experience. In: TURNER, V. W.; BRUNER, E. M. (Eds.). The anthropology of experience. Urbana: University of Illinois Press, 1986.

ADAMSON, G.; JONES, W.; TAPP, A. From CRM to FRM: Applying CRM in the football industry. Jornal of Database Marketing \& Customer Strategy Management. v. 13, n. 2, p. 156-172. Jan 2006.

ALBA, G. R. Os efeitos do orgulho nos torcedores de Futebol: uma perspectiva de Marketing. 2012,168 f. Dissertação - Mestrado em Administração, Porto Alegre, Universidade Federal do Rio Grande do Sul, 2012.

ARNOLD, M. J.; REYNOLDS, K. E.; PONDER, N.; LUEG, J. E. Customer delight in a retail context: investigating delightful and terrible shopping experiences. Journal of Business Research, v. 58, n. 8, p.1132$1145,2005$.

BARBETTA, P. A. Estatística aplicada às ciências sociais. Florianópolis: Ed. UFSC, 2001.

BENAZZI, J. R. S. C.; BORGES, C. N. Emoção, exposição e vendas: análise do patrocínio realizado por marcas de artigos esportivos no futebol brasileiro. PUC Rio. 2008.

BRAKUS, J. J.; SCHMITT, B. H.; ZARANTONELLO, L. Brand Experience: What Is It? How Is It Measured? Does It affec Loyalty? Journal of Marketing, v. 73, n. 2, p. 52-68, 2009.

CAPELO, R. Receitas do futebol: Como 150 clubes arrecadam dinheiro. São Paulo. 2015. Disponível em: < http://www.rodrigocapelo.com/receitas-do-futebol/>. Acesso em: 18 dez. 2015.

CARÙ, A.; COVA, B. Revisiting consumption experience: a more humble but complete view of the concept. Marketing Theory, v. 3, n. 2, p. 267-286, 2003.

CORRAR, L. J.; PAULO, E.; DIAS FILHO, J. M. (organizadores). Análise multivariada: para os cursos de Administração, Ciências Contábeis e Economia. São Paulo: Atlas, 2009.

FLEURY, F. A.; ALEJANDRO, T. B; FELDMANN P. R; Considerações teóricas acerca do composto de Marketing esportivo. Podium Sport, Leisure and Tourism Review, v. 3, n. 1, 2014.

GASPAR, M. A.; MORAIS, D. M. G.; VALADA Jr., A. C.; DEBIA, C. A. Marketing esportivo: Um estudo das ações praticadas por grandes clubes de futebol do Brasil. Podium Sport, Leisure and Tourism Review, v. 3, n. $1,2014$.

GHOSE, K. Internal brand equity defines customer experience. Direct Marketing: An International Journal, v. 3, n. 3, p. 177-185, 2009.

GRYNBERG, C. A.; ROCHA, A. L. P. Modelos de mensuração do recall de patrocínios esportivos nos consumidores. Revista Eletrônica de Administração, v. 16, n. 3, set./dez., p. 318-342. Rio de Janeiro, 2010.

HAIR, JR., J. F.; BABIN, B.; MONEY, A. H.; SAMOUEL, P. Fundamentos de métodos de pesquisa em administração. Porto Alegre: Bookman, 2005.

HAIR, JR., J. F.; WOLFINBARGER, M. F.; ORTINAU, D. J.; BUSH, R. P. Fundamentos de pesquisa de Marketing. Porto Alegre: Bookman, 2010.

HARDY, S.; MULLIN, B. J.; SUTTON, W. A. Marketing esportivo. Porto Alegre: Bookman, 2004.

IBGE (Brasil). Instituto Brasileiro de Geografia e Estatística. Joinville. 2016. Disponível em: $<$ http://cidades.ibge.gov.br/painel/painel.php?codmun=420910>. Acesso em: 26 nov. 2016.

JACOBSON, B. The social psychology of the creation of a sports fan identity: A theoretical review of the literature. The Online Journal of Sport Psychology, Connecticut, v. 5, n. 2, p. 1-14, 2003.

JEC - Joinville Esporte Clube. Joinville, 2016. Disponível em: <http://jec.com.br/>. Acesso em: 01 out. 2017.

KELLER, K. L. Conceptualizing, measuring and managing customer-based brand equity. Journal of Marketing, v. 57, n. 3, p. 1-22., 1993.

KOTLER, P.; KELlER, K. L. Administração de Marketing. 14. ed. São Paulo: Pearson Prentice Hall, 2012.

MALAGRINO, F. A. F. Gestão das marcas dos clubes de futebol: como o Marketing esportivo potencializa o consumo do torcedor. Dissertação - Mestrado em Administração, Pontifícia Universidade Católica de São Paulo, São Paulo, SP, Brasil, 2011. 
MARTINEZ, E.; CHERNATONY, L. The effect of brand extension strategies upon brand image. Journal of Consumer Marketing, v. 21, n. 1, p. 39-50, 2004.

MATTAR, F. N.; MATTAR, M. Gestão de negócios esportivos. Rio de Janeiro: Elsevier, 2013.

MORAES, S. G.; STREHLAU, V. I.; FIGUEIREDO, C. C. País ou marca: influências na intenção de compra. REBRAE - Revista Brasileira de Estratégia, v. 6, n. 3, p. 221- 233, 2013.

MORGAN, M. J.; SUMMERS J. Marketing esportivo. São Paulo: Thomson Learning, 2008.

PIMENTEL, J. G. M. A relevância do profissionalismo no futebol e os impactos da credibilidade dos dirigentes na obtenção do patrocínio. 2011. 68f. (Dissertação mestrado) - Escola Brasileira de Administração Pública e de Empresas, Centro de Formação Acadêmica e Pesquisa, Fundação Getúlio Vargas, Rio de Janeiro, 2011.

PITTS, B. G.; STOTLAR, D. K. Fundamentos de Marketing esportivo. São Paulo: Phorte, 2002.

SÁ, B. M. B.; ALMEIDA, V. M. C. Motivação, seleção, ativação e mensuração do patrocínio esportivo. In: V Encontro de Marketing da ANPAD, Curitiba, p. 1-16, maio 2012.

SCHARF, E. R.; SOUSA, R. P. L.; SARQUIS, A. B.; BELZ, E. A experiência e mais dez: uma estratégia para vencer na Champions League. Gestão \& Regionalidade, v. 32, n. 96, p. 21-34, 2016.

SCHARF, E. R. O patrocínio do futebol como ferramenta do Marketing esportivo para a construção de brand awareness. Revista Economia \& Gestão, Minas Gerais, v. 10, n. 23, p. 80-99, 2010.

SOMOGGI, A. Receitas do futebol brasileiro na última década. Disponível em: $<$ http://www.meioemensagem.com.br/home/Marketing/ponto_de_vista/2013/08/09/

Receitasdofutebolbrasileironaultimadecada.html>.

VERGARA, S. C. Projetos e relatórios de pesquisa em administração. 3.ed. São Paulo: Atlas, 2000

WALTER N.; CLEFF T.; CHU G. Brand experience's influence on customer satisfaction and loyalty: a mirage in marketing research? International Journal of Management Research and Business Strategy, v. 2, n. 1, p. 130144, 2013.

YIN, R. Estudo de Caso: Planejamento e métodos. Porto Alegre: Bookman, 2005.

YUAN, Y. E.; WU, C. K. Relationships among experiential. Marketing, experiential value, and customer satisfaction. Journal of Hospitality \& Tourism Research, v. 32, n. 3, p. 387-410, 2008.

ZARDINI FILHO, C. E. O esporte como diferencial para obtenção de vantagem competitiva em empresas no Brasil. 2012. xix, 220 f., il. Dissertação (Mestrado em Educação Física), Universidade de Brasília, Brasília, 2012.

ZIKMUND, W. G.; BABIN, B. J. Princípios da pesquisa de Marketing. São Paulo: Cengage Learning, 2011. 